\title{
Recoupling the Cardiac Nitric Oxide Synthases: Tetrahydrobiopterin Synthesis and Recycling
}

\author{
Matthew S. Alkaitis • Mark J. Crabtree
}

Published online: 19 June 2012

(C) The Author(s) 2012. This article is published with open access at Springerlink.com

\begin{abstract}
Nitric oxide (NO), a key regulator of cardiovascular function, is synthesized from L-arginine and oxygen by the enzyme nitric oxide synthase (NOS). This reaction requires tetrahydrobiopterin (BH4) as a cofactor. $\mathrm{BH} 4$ is synthesized from guanosine triphosphate (GTP) by GTP cyclohydrolase I (GTPCH) and recycled from 7,8-dihydrobiopterin (BH2) by dihydrofolate reductase. Under conditions of low $\mathrm{BH} 4$ bioavailability relative to $\mathrm{NOS}$ or $\mathrm{BH} 2$, oxygen activation is "uncoupled" from L-arginine oxidation, and NOS produces superoxide $\left(\mathrm{O}_{2}{ }^{-}\right)$instead of NO. NOS-derived superoxide reacts with NO to produce peroxynitrite $\left(\mathrm{ONOO}^{-}\right)$, a highly reactive anion that rapidly oxidizes $\mathrm{BH} 4$ and propagates NOS uncoupling. BH4 depletion and NOS uncoupling contribute to overload-induced heart failure, hypertension, ischemia/reperfusion injury, and atrial fibrillation. L-arginine depletion, methylarginine accumulation, and S-glutathionylation of NOS also promote uncoupling. Recoupling NOS is a promising approach to treating myocardial and vascular dysfunction associated with heart failure.
\end{abstract}

M. S. Alkaitis

Nuffield Department of Clinical Laboratory Sciences,

University of Oxford, John Radcliffe Hospital,

Oxford, UK

\section{S. Alkaitis}

Laboratory of Malaria and Vector Research, National Institute of Allergy and Infectious Diseases, National Institutes of Health, Bethesda, MD, USA

\section{J. Crabtree $(\square)$}

Department of Cardiovascular Medicine, University of Oxford, John Radcliffe Hospital,

Oxford, UK

e-mail: mark.crabtree@well.ox.ac.uk
Keywords Nitric oxide $\cdot$ Nitric oxide synthase . Uncoupling · Superoxide · Tetrahydrobiopterin . Dihydrobiopterin - Sepiapterin · Sapropterin · GTP cyclohydrolase I · Dihydrofolate reductase $\cdot$ Endothelial cell $\cdot$ Cardiomyocyte $\cdot$ Hypertension $\cdot$ Heart failure . Atrial fibrillation · Ischemia $\cdot$ Reperfusion · Vasodilation . L-Arginine $\cdot$ Monomethylarginine $\cdot$ Asymmetric dimethylarginine $\cdot$ S-Glutathionylation $\cdot$ Peroxynitrite . Oxidative stress $\cdot$ NADPH oxidase

\section{Introduction}

Synthesis of the gaseous signaling molecule nitric oxide (NO) by the nitric oxide synthase (NOS) family of enzymes is a key mechanism of cardiovascular homeostasis. Three NOS isoforms, neuronal (nNOS), inducible (iNOS), and endothelial (eNOS), catalyze the reaction of molecular oxygen with the amino acid substrate L-arginine to produce L-citrulline and NO [1]. During this reaction, electrons donated by nicotinamide adenine dinucleotide phosphate (NADPH) at the carboxy-terminal reductase domain of NOS are passed to the heme catalytic center of the oxidase domain, where activation of molecular oxygen is "coupled" to NO synthesis by two successive monooxygenations of L-arginine [2]. The cofactor 6R-5,6,7,8-tetrahydrobiopterin (BH4) is required for these reactions; in its absence, electron flow to molecular oxygen becomes "uncoupled" from L-arginine oxidation, resulting in production of superoxide $\left(\mathrm{O}_{2}{ }^{-}\right)$instead of $\mathrm{NO}$ [3-6]. The combination of increased oxidative stress and impaired $\mathrm{NO}$ signaling resulting from NOS uncoupling has been implicated in the pathogenesis of a wide range of disease states, including atherosclerosis [7], hypertension [8,9] and diabetes [10]. Advances in understanding the role of NO signaling in myocardial function have encouraged recent research into whether 
NOS uncoupling contributes to the pathogenesis of several aspects of heart failure. In this review, we will discuss current progress in this field, focusing on key studies that have identified BH4 bioavailability as a critical biochemical determinant of NOS uncoupling.

\section{BH4 Synthesis is a Determinant of NOS Uncoupling}

\section{BH4 as a NOS Cofactor}

Tetrahydrobiopterin was initially recognized as a cofactor required for enzymatic hydroxylation of phenylalanine, tyrosine, and tryptophan. Subsequently, the identity of the vasodilator known as "endothelial-derived relaxing factor" was discovered to be NO [11, 12], and BH4 also was found to be essential for NOS-mediated NO synthesis [13, 14]. As an NOS cofactor, BH4 performs both structural and biochemical functions. Structurally, BH4 stabilizes the active NOS homodimer $[15,16]$ and induces conformational changes that promote catalytic activity [17]. Biochemically, the donation of an electron by $\mathrm{BH} 4$ to produce a transient $\mathrm{BH} 4^{{ }^{*}}{ }^{+}$radical is required for the oxidation of $\mathrm{L}$-arginine to L-citrulline [18-20] and associated formation of a ferrous iron-NO complex at the NOS heme catalytic center [1,2]. In the final step of $\mathrm{NO}$ synthesis, $\mathrm{BH} 4^{\cdot+}$ recaptures an electron from this ferrous iron-NO complex, allowing release of gaseous $\mathrm{NO}[18,21]$. Therefore, $\mathrm{BH} 4$ is not consumed during NOS catalysis, but is necessary for both $\mathrm{NO}$ synthesis and release. However, BH4 is not required for the initiating step of NO synthesis, which consists of reduction of the heme iron by NADPH-derived electrons so that molecular oxygen may be bound and activated [20]. In the absence of BH4, NADPH consumption and oxygen activation proceed, but are no longer "coupled" to subsequent BH4-dependent L-arginine oxygenation [3-5]. As a result, activated oxygen is released directly from the heme catalytic center as superoxide in a process termed "NOS uncoupling" [3-5]. The addition of increasing concentrations of BH4 effectively reverses NOS uncoupling by proportionally reducing superoxide production and restoring NO synthesis [5]. De novo BH4 synthesis is a central mechanism by which sufficient cellular BH4 concentrations are maintained to support coupled NOS activity.

\section{BH4 Biosynthesis}

BH4 is a heterocyclic nitrogenous molecule derived from guanosine-5'-triphosphate (GTP). The enzymes GTP cyclohydrolase I (GTPCH), 6-pyruvoyl tetrahydrobiopterin synthase (PTPS), and sepiapterin reductase (SPR) catalyze successive steps in BH4 biosynthesis [22]. In most mammalian tissue, GTPCH-regulated conversion of GTP to 7,8dihydroneopterin triphosphate is the rate-limiting step in this pathway. As a result, $\mathrm{BH} 4$ concentrations correlate strongly with GTPCH expression [23]. Transcription-level regulation is primarily responsible for increased $\mathrm{BH} 4$ synthesis in endothelial cells [24] and cardiomyocytes [25] in response to proinflammatory cytokine signaling. However, GTPCH also may be regulated post-transcriptionally by protein-protein interaction with GTPCH feedback regulatory protein (GFRP), which mediates feedback inhibition of GTPCH by BH4 [26, 27]. In contrast, disruption of GTPCH-GFRP binding may explain phosphorylation-dependent upregulation of GTPCH activity in response to endothelial shear stress $[28,29]$. However, the importance of GFRP regulation may be overshadowed by transcription-level regulation of GTPCH, as evidenced by stable intracellular BH4 concentrations following GFRP overexpression or knockdown in endothelial cells [23].

\section{BH4: NOS Stoichiometry}

By increasing cellular BH4 concentrations, endothelial GTPCH overexpression improves coupled NOS activity in both cells [30] and mouse tissue [10]. Conversely, GTPCH knockdown reduces cellular BH4 concentrations, impairs coupled NOS activity, and increases superoxide production [31]. Furthermore, the ratio of $\mathrm{BH} 4$ to eNOS protein correlates strongly with NOS-dependent superoxide production across a range of GTPCH and eNOS expression levels [31]. These findings suggest that absolute cellular $\mathrm{BH} 4$ concentrations influence NOS coupling insofar as they reflect the ratio of BH4 to NOS protein. This concept may explain why transgenic overexpression of eNOS (thereby reducing the BH4: eNOS ratio) increases aortic and cardiac superoxide production in mice [32] and accelerates plaque formation in the apolipoprotein E-knockout model of atherosclerosis [33]. Restoration of BH4:eNOS stoichiometry by pharmacological BH4 supplementation [33] or concomitant overexpression of transgenic $\mathrm{GCH1}$ [32] attenuates superoxide production and disease pathogenesis. The clinical relevance of GTPCH expression is illustrated by the association of a relatively common $\mathrm{GCH} 1$ polymorphism with reduced $\mathrm{BH} 4$ production, reduced renal excretion of $\mathrm{NO}$ metabolites and evidence of NOS uncoupling in ex vivo vessels $[34,35]$. These studies taken together demonstrate that GTPCH expression and activity play an important role in determining cellular $\mathrm{BH} 4$, the ratio of BH4 to NOS protein, and NOS uncoupling.

\section{BH4 Recycling is a Determinant of NOS Uncoupling}

\section{BH4 Oxidation}

BH4 may be oxidized to 7,8-dihydrobiopterin $(7,8-\mathrm{BH} 2)$ or quinoid-dihydrobiopterin (q-BH2) by two distinct mechanisms. 
BH4 undergoes oxidation to $\mathrm{q}-\mathrm{BH} 2$ as a result of participating as a cofactor in the enzymatic hydroxylation of phenylalanine, tyrosine, or tryptophan. In the vascular endothelium, BH4 is not consumed by participating in NOS catalysis; instead, the primary mechanism of $\mathrm{BH} 4$ consumption is direct oxidation by cellular oxidants. The most abundant product of such oxidation reactions at physiological $\mathrm{pH}$ is 7,8-dihydrobiopterin (BH2), which competes with reduced $\mathrm{BH} 4$ for binding sites at the NOS oxidase domain [36]. However, because $\mathrm{BH} 2$ lacks the ability to supply reductive electrons required for L-arginine oxygenation, the displacement of $\mathrm{BH} 4$ by $\mathrm{BH} 2$ results in NOS uncoupling [5]. In a physiological setting, high levels of cellular oxidative stress contribute to NOS uncoupling by reducing the abundance of $\mathrm{BH} 4$ relative to $\mathrm{BH} 2$, thereby decreasing the proportion of NOS protein bound by catalytically active BH4. Thus, NOS uncoupling is influenced by the stoichiometric ratio of $\mathrm{BH} 4$ to $\mathrm{BH} 2$ as well as the ratio of $\mathrm{BH} 4$ to NOS protein [5]. In patients with coronary artery disease, both tissue $\mathrm{BH} 4$ concentrations and $\mathrm{BH} 4$ to $\mathrm{BH} 2$ ratios correlate with superoxide production and acetylcholine-mediated vasodilation [37].

\section{BH4 Recycling}

Dihydrofolate reductase (DHFR) is the enzyme responsible for recycling 7,8-BH2 back to catalytically-active $\mathrm{BH} 4$ using reductive electrons from NADPH [38]. Pharmacological DHFR inhibition (methotrexate treatment) or short interfering RNA knockdown of DHFR expression both result in significantly reduced levels of $\mathrm{BH} 4$ relative to $\mathrm{BH} 2$ [39•, 40]. Although DHFR inhibition does not alter total cellular biopterin concentrations, this reduction in the ratio of $\mathrm{BH} 4$ to $\mathrm{BH} 2$ is sufficient to increase superoxide production and inhibit L-arginine to L-citrulline conversion, a measure of coupled NOS activity [39•, 40]. Alternately, a similar effect may be achieved by GTPCH knockdown, which decreases cellular concentrations of all biopterins without altering the ratio of $\mathrm{BH} 4$ to $\mathrm{BH} 2[31,39 \bullet, 40]$. Concomitant DHFR and GTPCH knockdown increases superoxide production compared to knockdown of either gene alone [39•]. This finding demonstrates that NOS uncoupling is determined by $\mathrm{BH} 4$ stoichiometry relative to both $\mathrm{BH} 2$ and NOS. The functional interdependence of these ratios may explain why the effects of DHFR inhibition on NOS coupling are significantly stronger in mice with low tissue concentrations of $\mathrm{BH} 4$ due to reduced basal GTPCH expression [41]. BH4 recycling may also play a key role in $\mathrm{BH} 4$ transport, which is sensitive to DHFR inhibition in vivo [42]. Furthermore, injection of mice with equal parts $6 \mathrm{~S}-\mathrm{BH} 4$ and $6 \mathrm{R}-\mathrm{BH} 4$ results in tissue accumulation of primarily 6R-BH4 [42]. These findings suggest that the primary mechanism of BH4 transport across the plasma membrane is via oxidation to $\mathrm{BH} 2$, an achiral compound, and subsequent reduction to bioactive 6R-BH4 within the cell.

\section{BH4 Oxidation is a Cause and Consequence of NOS Uncoupling}

Superoxide derived from uncoupled NOS or other mechanisms is a critical source of cellular oxidative stress, including BH4 oxidation. Direct BH4 oxidation by superoxide is relatively slow [43], but $\mathrm{BH} 4$ is rapidly oxidized to $\mathrm{BH} 2$ by peroxynitrite $\left(\mathrm{ONOO}^{-}\right)[44,45]$, a highly reactive anion produced by the reaction of superoxide with NO [46]. Peroxynitrite also causes significant cellular damage by nitrating amino acid side chain thiol and hydroxyl groups, thereby disrupting enzymatic function. Consequently, the implications of NOS uncoupling include 1) reduced de novo NO production; 2) sequestration of bioactive NO by superoxide anions via peroxynitrite formation; 3) superoxide and peroxynitritemediated cellular damage; and 4) peroxynitrite-mediated oxidation of $\mathrm{BH} 4$ to $\mathrm{BH} 2$, resulting in further propagation of NOS uncoupling. Therefore, NOS uncoupling is a selfreinforcing biochemical state driven by $\mathrm{BH} 4$ oxidation (Fig. 1). BH4 oxidation due to uncoupled eNOS-dependent oxidative stress was observed both in vitro [31] and in vivo [32]. In these experiments, uncoupling was induced by increasing eNOS expression under conditions of stable GTPCH expression, effectively reducing the ratio of $\mathrm{BH} 4$ to eNOS [31, 32]. With all other variables held constant, the resulting oxidation of $\mathrm{BH} 4$ to $\mathrm{BH} 2$ can only be attributed to superoxide production by uncoupled NOS.

Cellular superoxide is also produced by a number of other mechanisms, including NADPH oxidase [8, 47, 48•], xanthine oxidase [49], and mitochondrial respiration [50]. During disease pathogenesis, oxidative stress from one or more of these sources could contribute to $\mathrm{BH} 4$ oxidation, thereby initiating or maintaining NOS uncoupling $[8,48 \bullet]$. Additional superoxide resulting from initial $\mathrm{BH} 4$ oxidation and NOS uncoupling would promote a cycle of cellular damage, further BH4 oxidation and biochemical stabilization of uncoupled NOS activity (Fig. 1). Interruption of this feed-forward process is a promising strategy for the treatment of a wide range of cardiovascular disease states caused or exacerbated by NOS uncoupling.

\section{Roles of NOS in Cardiac Physiology and Pathophysiology}

Coronary Blood Flow and Myocardial Function

NO maintains vascular tone by diffusing to the smooth muscle cells in the vascular wall and activating soluble 


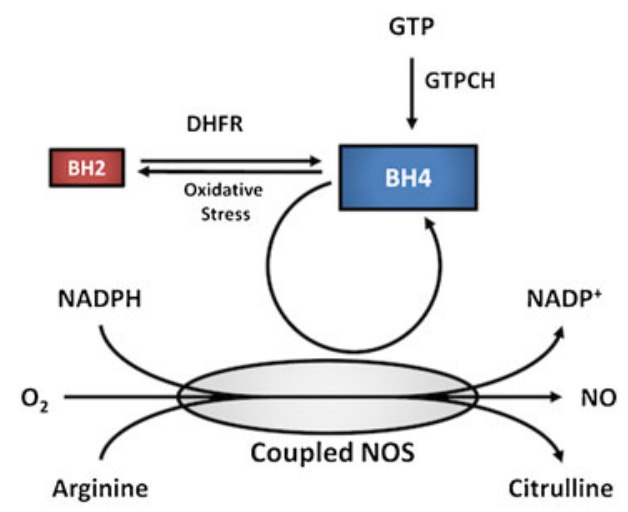

Fig. 1 BH4 synthesis, recycling, and oxidation as determinants of NOS uncoupling. Left To produce nitric oxide (NO), nitric oxide synthase (NOS) enzymes require the substrates L-arginine and molecular oxygen $\left(\mathrm{O}_{2}\right)$ and the cofactors tetrahydrobiopterin (BH4), reduced nicotinamide adenine diphosphate (NADPH), heme (not pictured), flavin mononucleotide (FMN, not pictured), and flavin adenine dinucleotide (FAD, not pictured). Under normal conditions, BH4 bioavailability is maintained by 1) de novo synthesis from guanosine triphosphate (GTP), in which the rate-limiting step is catalyzed by GTP cyclohydrolase (GTPCH) and 2) dihydrofolate reductase (DHFR)-mediated recycling of 7,8-dihydrobiopterin (BH2), the primary product of nonenzymatic BH4 oxidation. Right "Uncoupled" NOS

guanylate cyclase to produce cyclic GMP, which in turn modulates calcium influx and smooth muscle contractility. This pathway is the primary mechanism underlying endothelium-dependent vasodilation in response to shear stress or cholinergic stimulation [51]. In the myocardium, NO signaling is therefore an important regulator of both basal blood flow and induced vessel dilation [52]. However, cardiomyocytes also express functional eNOS [53], nNOS $[54,55]$, and, after cytokine stimulation, iNOS [56]. The major functions of endogenous NOS activity in the myocardium include modulation of cholinergic and $\beta$-adrenergic responsiveness [55, 57], stretch-induced $\mathrm{Ca}^{2+}$ handling in cardiomyocytes [58], and whole-heart contractility in response to volume loading [59]. BH4 bioavailability plays an important role in supporting myocardial NO production, as evidenced by increased basal heart rate and $\beta$-adrenergic responsiveness in mice with reduced GTPCH expression [60]. Further discussion of the complexities of subcellular NOS targeting and physiological roles in the myocardium are available elsewhere $[61,62]$.

\section{Overload-induced Heart Failure}

One of the first assessments of NOS uncoupling in the context of heart failure was conducted using transaortic constriction in mice as a model of chronic ventricular pressure overload [63]. In the weeks following aortic constriction, untreated wild-type mice develop cardiac hypertrophy,

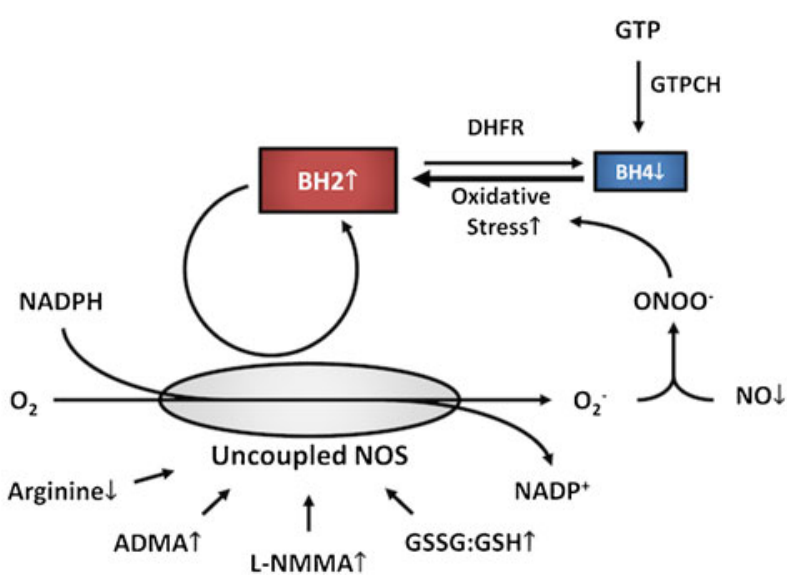

is characterized by production of superoxide $\left(\mathrm{O}_{2}{ }^{-}\right)$. NOS uncoupling is promoted by reduced $\mathrm{BH} 4$ bioavailability relative to either $\mathrm{BH} 2$ or NOS protein. In turn, $\mathrm{O}_{2}^{-}$produced by uncoupled NOS reacts with $\mathrm{NO}$, forming peroxynitrite $\left(\mathrm{ONOO}^{-}\right)$, a highly reactive anion that rapidly oxidizes BH4. Therefore, a state of NOS uncoupling is stabilized by self-propagating oxidative stress. In addition to this primary BH4-mediated cycle, additional mechanisms have been shown to promote uncoupling, including reduced arginine bioavailability, high levels of oxidized glutathione (GSSG) relative to reduced glutathione (GSH), or increased concentrations of the endogenous NOS inhibitors L- $N$-monomethylarginine (L-NMMA) and asymmetric dimethylarginine (ADMA)

structural remodeling, increased myocardial superoxide production, and, ultimately ventricular dysfunction [63]. Recoupling of NOS via BH4 supplementation reverses these effects and improves cardiac function at 9 weeks of constriction, but similar effects were also achieved by complete knockout of eNOS [63]. These findings suggest that oxidant stress due to eNOS uncoupling is a central mechanism underlying overload-induced heart failure. Follow-up studies using the same model showed that BH4 supplementation can also treat established cardiac dysfunction (4 weeks of transaortic constriction), significantly reversing superoxide production, and improving left ventricular function by 9 weeks after introduction of cardiac overload [64]. Importantly, these studies showed that reversal of cardiac dysfunction cannot be achieved with tetrahydroneopterin or tempol, compounds that exhibit antioxidant properties but are unable to recouple NOS $[63,64]$.

\section{Hypertension and Associated Cardiac Dysfunction}

The importance of eNOS as a regulator of systemic blood pressure is well-established [65], and the net impact of all three NOS isoforms in maintaining cardiovascular homeostasis was recently assessed in triple knockout mice [66]. Studies in mice with hypertension due to treatment with deoxycorticosterone acetate (DOCA) demonstrated that NOS uncoupling is a critical molecular mechanism involved in the development of hypertension $[8,9]$. Aortas harvested 
from DOCA-treated mice demonstrate evidence of $\mathrm{BH} 4$ oxidation, increased superoxide production, and reduced L-arginine to L-citrulline conversion [8]. These effects are eNOS-specific and responsive to $\mathrm{BH} 4$ treatment [8] or overexpression of GTPCH [9]. BH4 supplementation also has been shown to recouple NOS and reverse endothelial dysfunction associated with pulmonary hypertension [67] or following infusion with angiotensin II [68] or ACTH [69]. In addition to influencing coronary blood supply, systemic hypertension also determines cardiac loading and represents an important risk factor associated with heart failure. In subsequent in vivo studies, DOCA treatment was shown to result in significant left ventricular diastolic dysfunction associated with BH4 oxidation and NOS uncoupling in the myocardium [70•]. Ventricular diastolic dysfunction can be reversed by treatment with $\mathrm{BH} 4$, but not the smooth muscle-targeted vasodilator hydralazine, indicating the therapeutic importance of recoupling NOS as opposed to normalizing blood pressure alone [70•].

\section{Ischemia/Reperfusion Injury}

Cardiac ischemia followed by reperfusion results in significant BH4 oxidation, NOS uncoupling, endothelial dysfunction in coronary arterioles, and impaired coronary blood flow [71, 72]. BH4 supplementation partially inhibits superoxide production and restores $\mathrm{NO}$ production in isolated rat hearts [71]. Treatment with BH4 or the BH4 precursor sepiapterin also restores endothelium-dependent vasorelaxation in isolated coronary arterioles and improves ventricular function following ischemia/reperfusion injury [72-74]. However, the ability of $\mathrm{BH} 4$ to restore $\mathrm{NO}$ production decreases after $30 \mathrm{~min}$ and is absent after $90 \mathrm{~min}$ of ischemia in isolated rat hearts, suggesting that mechanisms in addition to BH4 depletion also contribute to NOS uncoupling induced by prolonged ischemia [71].

\section{Atrial Fibrillation}

Atrial NO synthesis is reduced in a porcine model of atrial fibrillation [75], and atrial production of superoxide and peroxynitrite is correlated with risk of developing atrial fibrillation in patients undergoing cardiac surgery [76]. In a recent study pairing data from a goat model with data from patients receiving cardiac surgery, NADPH oxidase was found to be an important source of atrial superoxide production in patients with postoperative atrial fibrillation and in goats after 2 weeks of induced fibrillation [48 ${ }^{\circ}$. In contrast, BH4 depletion and atrial superoxide production by uncoupled NOS are increased in patients with permanent atrial fibrillation and goats subjected to 6 months of induced fibrillation [48•]. These data suggest that initial oxidative stress from NADPH oxidase may ultimately lead to permanent atrial fibrillation by depleting $\mathrm{BH} 4$ and establishing a steady state of NOS uncoupling.

\section{Additional Mechanisms of NOS Uncoupling}

L-Arginine Bioavailability

The role of L-arginine bioavailability in determining NOS uncoupling was first illustrated by experiments in nNOStransfected cells that demonstrated increased peroxynitritemediated cellular damage under conditions of L-arginine depletion [77]. Subsequent studies in isolated nNOS and eNOS enzymes suggest that the effect of L-arginine depletion depends on NOS isoform, as well as on the presence of $\mathrm{BH} 4$. In isolated, $\mathrm{BH} 4$-replete $\mathrm{nNOS}$, superoxide production is significantly increased in the absence of L-arginine [78]. This finding suggests that despite the presence of $\mathrm{BH} 4$, nNOS ejects activated oxygen as superoxide with greater frequency when L-arginine substrate is not available for further reactions. In the absence of $\mathrm{BH} 4$, superoxide production by nNOS is maximal and independent of L-arginine availability [78]. In isolated, BH4-depleted eNOS enzyme, however, superoxide production is in fact stimulated by Larginine levels [79]. These results suggest that in the absence of $\mathrm{BH} 4$, the introduction of L-arginine may induce conformational changes in eNOS that promote electron flow and increase superoxide production if BH4 is not available to couple oxygen activation to L-arginine oxidation. This interpretation is supported by the observation that Larginine dose-dependently increases NADPH consumption by BH4-depleted eNOS [79].

\section{Accumulation of Methylarginines}

Methylated L-arginine species, including L- $N$-monomethylarginine (L-NMMA) and $\omega-N^{G}, N^{G}$-asymmetric dimethylarginine (ADMA), are produced by post-translational methylation of L-arginine residues by protein methyltransferases and liberated by subsequent proteolysis [80]. ADMA and L-NMMA may therefore accumulate due to increased methyltransferase activity [81] and/or inhibition of dimethylarginine dimethylaminohydrolase (DDAH), the enzyme responsible for ADMA catabolism [82]. Both L-NMMA and ADMA inhibit NOS-mediated NO production by competing with L-arginine to bind at the NOS catalytic site [83]. Under conditions of $\mathrm{BH} 4$ depletion, however, L-NMMA increases nNOS-mediated superoxide production and both L-NMMA and ADMA increase NADPH consumption and superoxide production by eNOS [78, 79]. In conjunction with $\mathrm{BH} 4$ depletion, accumulation of methylarginines may therefore contribute to NOS uncoupling in the context of endothelial or myocardial dysfunction. In support of this hypothesis, a 
study of patients undergoing coronary artery bypass surgery demonstrated that increased plasma ADMA concentrations correlate with reduced vasodilation and increased superoxide production in ex vivo vessels [84].

\section{S-Glutathionylation}

S-glutathionylation involves the binding of a glutathione tripeptide to the thiol group of an available cysteine residue. In a recent study, S-glutathionylation of two critical eNOS cysteine residues (C689 and C908) significantly inhibited NO production and increased superoxide production [85••]. Furthermore, increased glutathionylation in the aortic rings of oxidant-treated or spontaneously hypertensive rats impaired eNOS-dependent vasorelaxation following acetylcholine stimulation [85*0]. The authors of this study speculate that superoxide production following Sglutathionylation occurs at the reductase domain, rather than at the heme catalytic center [85••], although further experimentation is needed to conclusively differentiate these two potential mechanisms of superoxide production.

\section{Recoupling NOS as a Therapeutic Approach}

\section{L-Arginine Supplementation}

L-arginine supplementation has been pursued as a potential approach to restoring NOS-mediated NO production in patients with cardiovascular disease states characterized by endothelial dysfunction. However, completed clinical trials have largely failed to show beneficial effects, and in some cases demonstrated evidence of harm. For example, $3 \mathrm{~g}$ of L-arginine per day delivered orally for 6 months resulted in impaired flow-mediated vasodilation, reduced vascular compliance, and low plasma and urinary nitrites and nitrates in a cohort study of patients with peripheral arterial disease [86]. In addition, patients receiving L-arginine also scored lower on treadmill assessments of exercise capacity compared to placebo-treated control patients. Similarly, treatment with $3 \mathrm{~g}$ of L-arginine three times daily for 6 months failed to produce a significant effect on ejection fraction or vascular stiffness in a study of patients who suffered myocardial infarction [87]. The group receiving L-arginine treatment did, however, exhibit a higher death rate than the control group leading to closure of enrollment due to safety concerns [87]. Can the general lack of efficacy of L-arginine supplementation be ascribed to the failure to also replete BH4? Based on available biochemical data [78, 79], supplementation of $\mathrm{L}$-arginine under conditions of $\mathrm{BH} 4$ depletion is not only insufficient to recouple NOS, but in fact exacerbates NOS uncoupling. Therefore, administration of L-arginine alone would not be expected to improve endothelial function in disease states characterized by $\mathrm{BH} 4$ depletion.

\section{BH4 Supplementation}

BH4 supplementation as a therapeutic approach promises the possibility of improving endothelial dysfunction while reducing the risk of hypotension associated with therapies aimed at downstream NO signaling targets. Several physiological experiments have demonstrated improved eNOSdependent vasodilation following $\mathrm{BH} 4$ infusion in individuals with hypertension [88], hypercholesterolemia [89], diabetes [90], or a history of smoking [91]. Early small trials also demonstrated that oral $\mathrm{BH} 4$ administration improved forearm blood flow in hypercholestrolemic patients [92] and reduced blood pressure in patients with poorly controlled hypertension [93]. However, these studies were limited in scope, largely due to the instability of $\mathrm{BH} 4$ preparations for oral delivery. In 2007, the U.S. Food and Drug Administration approved use of sapropterin, a thermo- and photostable, orally available preparation of synthetic 6R-BH4 (trade name: Kuvan [manufactured by Biomarin Pharmaceutical, Inc., Novato, CA]) for the treatment of phenylketonuria (PKU). PKU is a metabolic disorder resulting from a loss-of-function mutation in the BH4-dependent enzyme phenylalanine hydroxylase that is characterized by accumulation of plasma phenylalanine and potentially severe neurological complications. Large phase 3 trials in this patient population demonstrated that sapropterin was well-tolerated and significantly reduced plasma phenylalanine levels by 1 week of therapy $[94,95]$. The efficacy and safety profiles demonstrated in these trials resulted in high interest in sapropterin as a potential treatment for cardiovascular disease characterized by endothelial dysfunction. In a study of patients with sickle cell disease, initial results suggested some improvement in reactive forearm vasodilation following sustained treatment with sapropterin. However, trials in patients with systemic or pulmonary hypertension failed to demonstrate significant efficacy, and full data on these and most other registered studies have yet to be published (Table 1).

Despite this general lack of published clinical trial data, a recent report on sapropterin treatment in patients with coronary artery disease provides some mechanistic insight into the limitations of oral BH4 supplementation as a therapeutic approach to treating cardiovascular disease [96••]. In this study, oral sapropterin treatment failed to improve brachial flow-mediated vasodilation, aortic or carotid distensibility, or acetylcholine-induced vasodilation in ex vivo saphenous vein rings [96••]. Plasma and saphenous vein tissue BH4 concentrations were higher in patients receiving sapropterin treatment compared to placebo-treated control patients, but a concomitant increase in $\mathrm{BH} 2$ concentrations yielded no 
Table 1 Clinical trials of oral sapropterin

\begin{tabular}{|c|c|c|c|c|}
\hline Disease state & Intervention & $\begin{array}{l}\text { Duration, } \\
w k\end{array}$ & Results & Clinical trial ID \\
\hline Systemic hypertension & Oral sapropterin, $5 \mathrm{mg} / \mathrm{kg}$, BID & 8 & $\begin{array}{l}\text { No statistically significant effect on SBP } \\
\text { vs placebo (http://www.bmrn.com/) }\end{array}$ & NCT00325962 \\
\hline $\begin{array}{l}\text { Pulmonary arterial } \\
\text { hypertension }\end{array}$ & $\begin{array}{l}\text { Oral sapropterin, dose escalation every } \\
2 \text { wks from } 2.5 \text { to } 5 \text { to } 10 \mathrm{mg} / \mathrm{kg} / \mathrm{d}+ \\
2 \mathrm{~d} \text { of } 20 \mathrm{mg} / \mathrm{kg} \text { BID }\end{array}$ & 6 & $\begin{array}{l}\text { No statistically significant effects vs } \\
\text { placebo (http://www.bmrn.com/) }\end{array}$ & NCT00435331 \\
\hline Sickle cell disease & $\begin{array}{l}\text { Oral sapropterin, dose escalation every } \\
4 \text { wks from } 2.5 \text { to } 5 \text { to } 10 \text { to } 20 \mathrm{mg} / \mathrm{kg} / \mathrm{d}\end{array}$ & 16 & $\begin{array}{l}\text { Improvement of RH-PAT at } 8,12 \text {, and } \\
16 \text { wks of treatment. Sapropterin was } \\
\text { well tolerated (http://www.bmrn.com/) }\end{array}$ & NCT00445978 \\
\hline Coronary artery disease & $400 \mathrm{mg} / \mathrm{d}$ or $700 \mathrm{mg} / \mathrm{d}$ & $2-6$ & $\begin{array}{l}\text { No statistically significant difference in } \\
\text { clinical end points or in dilation or } \\
\text { NOS coupling in ex vivo vessels }\end{array}$ & $\begin{array}{l}\text { NCT00423280, } \\
\text { see reference } \\
{[96 \bullet \bullet]}\end{array}$ \\
\hline Peripheral arterial disease & $400 \mathrm{mg}$ BID & 24 & $\begin{array}{l}\text { Not reported to date (Start date: Dec } \\
\text { 2006; est. completion: Jan 2009) }\end{array}$ & NCT00403494 \\
\hline Systolic hypertension & Oral sapropterin, $5 \mathrm{mg} / \mathrm{kg}$, BID & 8 & Not reported (Start date: Dec 2008) & NCT00802893 \\
\hline Chronic kidney disease & $\begin{array}{l}\text { Oral sapropterin, } 400 \mathrm{mg} \text { BID }+400 \mathrm{mg} \\
\text { vitamin C BID for the second } 6 \mathrm{wks}\end{array}$ & 12 & $\begin{array}{l}\text { Not reported to date (Start date: May } \\
\text { 2008; est. completion: Aug 2009) }\end{array}$ & NCT00625820 \\
\hline $\begin{array}{l}\text { All-cause endothelial } \\
\text { dysfunction }\end{array}$ & $\begin{array}{l}\text { Oral sapropterin, } 5 \mathrm{mg} / \mathrm{kg} \text { oral } \pm 500 \mathrm{mg} \\
\text { vitamin C BID }\end{array}$ & 2 & $\begin{array}{l}\text { Not reported to date (Start date: Sept } \\
\text { 2007; est. completion: March 2009) }\end{array}$ & NCT00532844 \\
\hline $\begin{array}{l}\text { Liver cirrhosis, portal } \\
\text { hypertension }\end{array}$ & $\begin{array}{l}\text { Oral sapropterin, dose escalation weekly } \\
\text { from } 5 \text { to } 10 \mathrm{mg} / \mathrm{kg} / \mathrm{d}\end{array}$ & 2 & $\begin{array}{l}\text { Ongoing (Start date: Oct 2011; est. } \\
\text { completion: Jan 2013) }\end{array}$ & NCT01456286 \\
\hline
\end{tabular}

Synthetic 6R-BH4, Trade name: Kuvan (manufactured by Biomarin Pharmaceutical Inc., Novato, CA)

$B I D$ twice daily; SBP systolic blood pressure; $R H$-PAT reactive hyperemia-peripheral arterial tonometry (a measurement of vasodilation following temporary constriction of the forearm); NOS nitric oxide synthase; est. estimated.

significant improvement in the ratio of $\mathrm{BH} 4$ to oxidized biopterin species, conversion of L-arginine to L-citrulline, or superoxide production [96••]. Furthermore, exogenous BH4 added to whole blood was rapidly oxidized and incubation of ex vivo saphenous vein rings with exogenous $\mathrm{BH} 4$ paradoxically reduced the ratio of $\mathrm{BH} 4$ to oxidized biopterins due to accumulation of $\mathrm{BH} 2$ [96*0]. The ability of BH4 to recouple NOS in patients with cardiovascular disease may therefore be limited by $\mathrm{BH} 4$ oxidation, $\mathrm{BH} 2$ accumulation, and failure to improve $\mathrm{BH} 4: \mathrm{BH} 2$ ratios. This limitation also has recently been recognized in an animal model of chronic pressure overloadinduced heart failure. Following increasing doses of $\mathrm{BH} 4$, assessment of myocardial biopterin levels showed that $\mathrm{BH} 2$ rose linearly, but $\mathrm{BH} 4$ plateaued at higher doses, resulting in $\mathrm{BH} 4: \mathrm{BH} 2$ ratios returning back toward baseline values [97•].

\section{Indirect Preservation of $\mathrm{BH} 4$}

Given these limitations of direct $\mathrm{BH} 4$ administration, therapeutic interventions aimed at improving or preserving endogenous $\mathrm{BH} 4$ bioavailability may represent a viable alternative. For example, the beneficial effects of statins may depend in part on their ability to increase $\mathrm{BH} 4$ bioavailability, as has been demonstrated both in vitro [98] and in patients [99]. By improving $\mathrm{BH} 4$ recycling and/or reducing oxidant stress, ascorbic acid [44] and 5-methyl-tetrahydrofolate [100] also have been shown to improve BH4 bioavailability and coupled NOS activity.

\section{Conclusions}

Reduced $\mathrm{BH} 4$ concentrations relative to cellular $\mathrm{BH} 2$ and NOS protein result in the uncoupling of oxygen activation from NO production and promote the generation of superoxide anions instead. Oxidative stress due to uncoupled NOS activity in turn leads to oxidation of $\mathrm{BH} 4$ to $\mathrm{BH} 2$ and further propagation of NOS uncoupling. NOS uncoupling and BH4 oxidation thus represent a self-perpetuating cycle that ultimately results in impaired NO signaling in addition to cellular damage and inflammation due to increased oxidative stress (Fig. 1). Restoration of $\mathrm{BH} 4$ bioavailability therefore represents a promising approach to recoupling NOS for the treatment of cardiovascular disease. However, early clinical trials of oral synthetic BH4 (sapropterin) thus far generally have failed to demonstrate efficacy in the treatment of diseases characterized by endothelial dysfunction (Table 1). These disappointing results may result from failure to improve the ratio of $\mathrm{BH} 4$ to $\mathrm{BH} 2$ [96••], highlighting the need for further research on cellular and systemic BH4 oxidation, trafficking and recycling. The clinical efficacy of improving BH4 bioavailability also may depend on other biochemical determinants of NOS uncoupling, including cellular concentrations of L-arginine, methylarginines, and oxidized glutathione. Future studies are therefore needed to understand how BH4 bioavailability and these factors interact with one another to determine NOS activity at biochemical, cellular, and systemic levels. Resulting advances could lead to significant improvement in 
the treatment of the wide range of cardiovascular disease states in which NOS uncoupling is a central pathogenic mechanism.

Disclosures No potential conflicts of interest relevant to this article were reported.

Open Access This article is distributed under the terms of the Creative Commons Attribution License which permits any use, distribution, and reproduction in any medium, provided the original author(s) and the source are credited.

\section{References}

Papers of particular interest, published recently, have been highlighted as:

- Of importance

- Of major importance

1. Daff S. NO synthase: structures and mechanisms. Nitric Oxide. 2010;23(1):1-11.

2. Stuehr DJ, Kwon NS, Nathan CF, et al. N omega-hydroxy-Larginine is an intermediate in the biosynthesis of nitric oxide from L-arginine. J Biol Chem. 1991;266(10):6259-63.

3. Vasquez-Vivar J, Kalyanaraman B, Martasek P, et al. Superoxide generation by endothelial nitric oxide synthase: the influence of cofactors. Proc Natl Acad Sci USA. 1998;95(16):9220-5.

4. Xia Y, Tsai AL, Berka V, Zweier JL. Superoxide generation from endothelial nitric-oxide synthase. A Ca2+/calmodulin-dependent and tetrahydrobiopterin regulatory process. J Biol Chem. 1998;273(40):25804-8.

5. Vasquez-Vivar J, Martasek P, Whitsett J, Joseph J, Kalyanaraman B. The ratio between tetrahydrobiopterin and oxidized tetrahydrobiopterin analogues controls superoxide release from endothelial nitric oxide synthase: an EPR spin trapping study. Biochem J. 2002;362(Pt 3):733-9.

6. Pou S, Pou WS, Bredt DS, Snyder SH, Rosen GM. Generation of superoxide by purified brain nitric oxide synthase. J Biol Chem. 1992;267(34):24173-6.

7. Hattori Y, Hattori S, Wang X, et al. Oral administration of tetrahydrobiopterin slows the progression of atherosclerosis in apolipoprotein E-knockout mice. Arterioscler Thromb Vasc Biol. 2007;27(4):865-70.

8. Landmesser U, Dikalov S, Price SR, et al. Oxidation of tetrahydrobiopterin leads to uncoupling of endothelial cell nitric oxide synthase in hypertension. J Clin Invest. 2003;111(8):1201-9.

9. Du YH, Guan YY, Alp NJ, Channon KM, Chen AF. Endothelium-specific GTP cyclohydrolase I overexpression attenuates blood pressure progression in salt-sensitive low-renin hypertension. Circulation. 2008;117(8):1045-54.

10. Alp NJ, Mussa S, Khoo J, et al. Tetrahydrobiopterin-dependent preservation of nitric oxide-mediated endothelial function in diabetes by targeted transgenic GTP-cyclohydrolase I overexpression. J Clin Invest. 2003;112(5):725-35.

11. Ignarro LJ, Buga GM, Wood KS, Byrns RE, Chaudhuri G. Endothelium-derived relaxing factor produced and released from artery and vein is nitric oxide. Proc Natl Acad Sci USA. 1987;84 (24):9265-9.
12. Palmer RM, Ferrige AG, Moncada S. Nitric oxide release accounts for the biological activity of endothelium-derived relaxing factor. Nature. 1987;327(6122):524-6.

13. Kwon NS, Nathan CF, Stuehr DJ. Reduced biopterin as a cofactor in the generation of nitrogen oxides by murine macrophages. $J$ Biol Chem. 1989;264(34):20496-501.

14. Tayeh MA, Marletta MA. Macrophage oxidation of L-arginine to nitric oxide, nitrite, and nitrate. Tetrahydrobiopterin is required as a cofactor. J Biol Chem. 1989;264(33):19654-8.

15. Baek KJ, Thiel BA, Lucas S, Stuehr DJ. Macrophage nitric oxide synthase subunits. Purification, characterization, and role of prosthetic groups and substrate in regulating their association into a dimeric enzyme. J Biol Chem. 1993;268(28):21120-9.

16. Klatt P, Schmidt K, Lehner D, et al. Structural analysis of porcine brain nitric oxide synthase reveals a role for tetrahydrobiopterin and L-arginine in the formation of an SDS-resistant dimer. EMBO J. 1995;14(15):3687-95.

17. Crane BR, Arvai AS, Ghosh DK, et al. Structure of nitric oxide synthase oxygenase dimer with pterin and substrate. Science (New York, NY). 1998;279(5359):2121-6.

18. Wei CC, Wang ZQ, Hemann C, Hille R, Stuehr DJ. A tetrahydrobiopterin radical forms and then becomes reduced during Nomega-hydroxyarginine oxidation by nitric-oxide synthase. J Biol Chem. 2003;278(47):46668-73.

19. Hurshman AR, Krebs C, Edmondson DE, Huynh BH, Marletta MA. Formation of a pterin radical in the reaction of the heme domain of inducible nitric oxide synthase with oxygen. Biochemistry. 1999;38(48):15689-96.

20. Wei CC, Wang ZQ, Wang Q, et al. Rapid kinetic studies link tetrahydrobiopterin radical formation to heme-dioxy reduction and arginine hydroxylation in inducible nitric-oxide synthase. J Biol Chem. 2001;276(1):315-9.

21. Wei CC, Wang ZQ, Tejero J, et al. Catalytic reduction of a tetrahydrobiopterin radical within nitric-oxide synthase. J Biol Chem. 2008;283(17):11734-42.

22. Thony B, Auerbach G, Blau N. Tetrahydrobiopterin biosynthesis, regeneration and functions. Biochem J. 2000;347(Pt 1):1-16.

23. Tatham AL, Crabtree MJ, Warrick N, et al. GTP cyclohydrolase I expression, protein, and activity determine intracellular tetrahydrobiopterin levels, independent of GTP cyclohydrolase feedback regulatory protein expression. J Biol Chem. 2009;284(20):13660-8.

24. Katusic ZS, Stelter A, Milstien S. Cytokines stimulate GTP cyclohydrolase I gene expression in cultured human umbilical vein endothelial cells. Arterioscler Thromb Vasc Biol. 1998;18 (1):27-32.

25. Kasai K, Hattori Y, Banba N, et al. Induction of tetrahydrobiopterin synthesis in rat cardiac myocytes: impact on cytokineinduced NO generation. Am J Physiol. 1997;273(2 Pt 2):H66572.

26. Harada T, Kagamiyama H, Hatakeyama K. Feedback regulation mechanisms for the control of GTP cyclohydrolase I activity. Science (New York, NY). 1993;260(5113):1507-10.

27. Milstien S, Jaffe H, Kowlessur D, Bonner TI. Purification and cloning of the GTP cyclohydrolase I feedback regulatory protein, GFRP. J Biol Chem. 1996;271(33):19743-51.

28. Li L, Rezvan A, Salerno JC, et al. GTP cyclohydrolase I phosphorylation and interaction with GTP cyclohydrolase feedback regulatory protein provide novel regulation of endothelial tetrahydrobiopterin and nitric oxide. Circ Res. 2010;106(2):328-36.

29. Du J, Wei N, Xu H, et al. Identification and functional characterization of phosphorylation sites on GTP cyclohydrolase I. Arterioscler Thromb Vasc Biol. 2009;29(12):2161-8.

30. Cai S, Alp NJ, McDonald D, et al. GTP cyclohydrolase I gene transfer augments intracellular tetrahydrobiopterin in human endothelial cells: effects on nitric oxide synthase activity, protein levels and dimerisation. Cardiovasc Res. 2002;55(4):838-49. 
31. Crabtree MJ, Tatham AL, Al-Wakeel Y, et al. Quantitative regulation of intracellular endothelial nitric-oxide synthase (eNOS) coupling by both tetrahydrobiopterin-eNOS stoichiometry and biopterin redox status: insights from cells with tet-regulated GTP cyclohydrolase I expression. J Biol Chem. 2009;284 (2): $1136-44$

32. Bendall JK, Alp NJ, Warrick N, et al. Stoichiometric relationships between endothelial tetrahydrobiopterin, endothelial NO synthase (eNOS) activity, and eNOS coupling in vivo: insights from transgenic mice with endothelial-targeted GTP cyclohydrolase 1 and eNOS overexpression. Circ Res. 2005;97(9):864-71.

33. Ozaki M, Kawashima S, Yamashita T, et al. Overexpression of endothelial nitric oxide synthase accelerates atherosclerotic lesion formation in apoE-deficient mice. J Clin Invest. 2002;110 (3):331-40.

34. Zhang L, Rao F, Zhang K, et al. Discovery of common human genetic variants of GTP cyclohydrolase 1 (GCH1) governing nitric oxide, autonomic activity, and cardiovascular risk. J Clin Invest. 2007;117(9):2658-71.

35. Antoniades C, Shirodaria C, Van Assche T, et al. GCH1 haplotype determines vascular and plasma biopterin availability in coronary artery disease effects on vascular superoxide production and endothelial function. J Am Coll Cardiol. 2008;52(2):158-65.

36. Crabtree MJ, Smith CL, Lam G, Goligorsky MS, Gross SS. Ratio of 5,6,7,8-tetrahydrobiopterin to 7,8-dihydrobiopterin in endothelial cells determines glucose-elicited changes in NO vs. superoxide production by eNOS. Am J Physiol Heart Circ Physiol. 2008;294(4):H1530-40.

37. Antoniades C, Shirodaria C, Crabtree M, et al. Altered plasma versus vascular biopterins in human atherosclerosis reveal relationships between endothelial nitric oxide synthase coupling, endothelial function, and inflammation. Circulation. 2007;116 (24):2851-9.

38. Curtius HC, Heintel D, Ghisla S, et al. Tetrahydrobiopterin biosynthesis. Studies with specifically labeled $(2 \mathrm{H}) \mathrm{NAD}(\mathrm{P}) \mathrm{H}$ and $2 \mathrm{H} 2 \mathrm{O}$ and of the enzymes involved. Eur J Biochem. 1985;148 (3):413-9.

39. - Crabtree MJ, Tatham AL, Hale AB, Alp NJ, Channon KM. Critical role for tetrahydrobiopterin recycling by dihydrofolate reductase in regulation of endothelial nitric-oxide synthase coupling: relative importance of the de novo biopterin synthesis versus salvage pathways. J Biol Chem. 2009;284(41):28128-36. This series of in vitro experiments identifies DHFR-mediated BH4 recycling as a key determinant of BH4:BH2 stoichiometry and NOS uncoupling.

40. Sugiyama T, Levy BD, Michel T. Tetrahydrobiopterin recycling, a key determinant of endothelial nitric-oxide synthase-dependent signaling pathways in cultured vascular endothelial cells. J Biol Chem. 2009;284(19):12691-700.

41. Crabtree MJ, Hale AB, Channon KM. Dihydrofolate reductase protects endothelial nitric oxide synthase from uncoupling in tetrahydrobiopterin deficiency. Free Radic Biol Med. 2011;50 (11):1639-46.

42. Sawabe K, Wakasugi KO, Hasegawa H. Tetrahydrobiopterin uptake in supplemental administration: elevation of tissue tetrahydrobiopterin in mice following uptake of the exogenously oxidized product 7,8-dihydrobiopterin and subsequent reduction by an anti-folatesensitive process. J Pharmacol Sci. 2004;96(2):124-33.

43. Vasquez-Vivar J, Whitsett J, Martasek P, Hogg N, Kalyanaraman B. Reaction of tetrahydrobiopterin with superoxide: EPR-kinetic analysis and characterization of the pteridine radical. Free Radic Biol Med. 2001;31(8):975-85.

44. Kuzkaya N, Weissmann N, Harrison DG, Dikalov S. Interactions of peroxynitrite, tetrahydrobiopterin, ascorbic acid, and thiols: implications for uncoupling endothelial nitric-oxide synthase. J Biol Chem. 2003;278(25):22546-54.
45. Beckman JS, Beckman TW, Chen J, Marshall PA, Freeman BA. Apparent hydroxyl radical production by peroxynitrite: implications for endothelial injury from nitric oxide and superoxide. Proc Natl Acad Sci USA. 1990;87(4):1620-4.

46. Milstien S, Katusic Z. Oxidation of tetrahydrobiopterin by peroxynitrite: implications for vascular endothelial function. Biochem Biophys Res Commun. 1999;263(3):681-4.

47. Rajagopalan S, Kurz S, Munzel T, et al. Angiotensin II-mediated hypertension in the rat increases vascular superoxide production via membrane NADH/NADPH oxidase activation. Contribution to alterations of vasomotor tone. J Clin Invest. 1996;97(8):191623.

48. • Reilly SN, Jayaram R, Nahar K, et al. Atrial sources of reactive oxygen species vary with the duration and substrate of atrial fibrillation: implications for the antiarrhythmic effect of statins. Circulation. 2011;124(10):1107-17. This report pairs a clinical study of patients undergoing cardiac surgery with experiments in a goat model of atrial fibrillation $(A F)$. The authors demonstrated that NADPH oxidase contributes to oxidative stress early in the development of $A F$, but that BH4 depletion and uncoupled NOS activity are more relevant in established AF.

49. Ohara Y, Peterson TE, Harrison DG. Hypercholesterolemia increases endothelial superoxide anion production. J Clin Invest. 1993;91(6):2546-51.

50. Murphy MP. How mitochondria produce reactive oxygen species. Biochem J. 2009;417(1):1-13.

51. Furchgott RF, Zawadzki JV. The obligatory role of endothelial cells in the relaxation of arterial smooth muscle by acetylcholine. Nature. 1980;288(5789):373-6.

52. Seddon M, Melikian N, Dworakowski R, et al. Effects of neuronal nitric oxide synthase on human coronary artery diameter and blood flow in vivo. Circulation. 2009;119(20):2656-62.

53. Balligand JL, Kobzik L, Han X, et al. Nitric oxide-dependent parasympathetic signaling is due to activation of constitutive endothelial (type III) nitric oxide synthase in cardiac myocytes. J Biol Chem. 1995;270(24):14582-6.

54. Xu KY, Huso DL, Dawson TM, Bredt DS, Becker LC. Nitric oxide synthase in cardiac sarcoplasmic reticulum. Proc Natl Acad Sci USA. 1999;96(2):657-62.

55. Ashley EA, Sears CE, Bryant SM, Watkins HC, Casadei B. Cardiac nitric oxide synthase 1 regulates basal and betaadrenergic contractility in murine ventricular myocytes. Circulation. 2002;105(25):3011-6.

56. Balligand JL, Ungureanu-Longrois D, Simmons WW, et al. Cytokine-inducible nitric oxide synthase (iNOS) expression in cardiac myocytes. Characterization and regulation of iNOS expression and detection of iNOS activity in single cardiac myocytes in vitro. J Biol Chem. 1994;269(44):27580-8.

57. Balligand JL, Kelly RA, Marsden PA, Smith TW, Michel T. Control of cardiac muscle cell function by an endogenous nitric oxide signaling system. Proc Natl Acad Sci USA. 1993;90(1):347-51.

58. Petroff MG, Kim SH, Pepe S, et al. Endogenous nitric oxide mechanisms mediate the stretch dependence of $\mathrm{Ca} 2+$ release in cardiomyocytes. Nat Cell Biol. 2001;3(10):867-73.

59. Prendergast BD, Sagach VF, Shah AM. Basal release of nitric oxide augments the Frank-Starling response in the isolated heart. Circulation. 1997;96(4):1320-9.

60. Adlam D, Herring N, Douglas G, et al. Regulation of betaadrenergic control of heart rate by GTP-cyclohydrolase 1 (GCH1) and tetrahydrobiopterin. Cardiovasc Res. 2012;93 (4):694-701.

61. Massion PB, Feron O, Dessy C, Balligand JL. Nitric oxide and cardiac function: ten years after, and continuing. Circ Res. 2003;93(5):388-98.

62. Zhang YH, Casadei B. Sub-cellular targeting of constitutive NOS in health and disease. J Mol Cell Cardiol. 2012;52(2):341-50. 
63. Takimoto E, Champion HC, Li M, et al. Oxidant stress from nitric oxide synthase-3 uncoupling stimulates cardiac pathologic remodeling from chronic pressure load. J Clin Invest. 2005;115(5):1221-31.

64. Moens AL, Takimoto E, Tocchetti CG, et al. Reversal of cardiac hypertrophy and fibrosis from pressure overload by tetrahydrobiopterin: efficacy of recoupling nitric oxide synthase as a therapeutic strategy. Circulation. 2008;117(20):2626-36.

65. Huang PL, Huang Z, Mashimo $\mathrm{H}$, et al. Hypertension in mice lacking the gene for endothelial nitric oxide synthase. Nature. 1995;377(6546):239-42.

66. Nakata S, Tsutsui M, Shimokawa H, et al. Spontaneous myocardial infarction in mice lacking all nitric oxide synthase isoforms. Circulation. 2008;117(17):2211-23.

67. Khoo JP, Zhao L, Alp NJ, et al. Pivotal role for endothelial tetrahydrobiopterin in pulmonary hypertension. Circulation. 2005;111(16):2126-33.

68. Kase H, Hashikabe Y, Uchida K, Nakanishi N, Hattori Y. Supplementation with tetrahydrobiopterin prevents the cardiovascular effects of angiotensin II-induced oxidative and nitrosative stress. J Hypertens. 2005;23(7):1375-82.

69. Zhang Y, Pang T, Earl J, et al. Role of tetrahydrobiopterin in adrenocorticotropic hormone-induced hypertension in the rat. Clin Exp Hypertens. 2004;26(3):231-41.

70. - Silberman GA, Fan TH, Liu H, et al. Uncoupled cardiac nitric oxide synthase mediates diastolic dysfunction. Circulation. 2010;121(4):519-28. Using a mouse model, Silberman and colleagues demonstrated that hypertension-induced left ventricular diastolic dysfunction is associated with BH4 oxidation and is amenable to BH4 supplementation.

71. Dumitrescu C, Biondi R, Xia Y, et al. Myocardial ischemia results in tetrahydrobiopterin (BH4) oxidation with impaired endothelial function ameliorated by BH4. Proc Natl Acad Sci USA. 2007;104 (38):15081-6.

72. Tiefenbacher CP, Chilian WM, Mitchell M, DeFily DV. Restoration of endothelium-dependent vasodilation after reperfusion injury by tetrahydrobiopterin. Circulation. 1996;94(6):1423-9.

73. Verma S, Maitland A, Weisel RD, et al. Novel cardioprotective effects of tetrahydrobiopterin after anoxia and reoxygenation: identifying cellular targets for pharmacologic manipulation. J Thorac Cardiovasc Surg. 2002;123(6):1074-83.

74. Yamashiro S, Noguchi K, Matsuzaki T, et al. Beneficial effect of tetrahydrobiopterin on ischemia-reperfusion injury in isolated perfused rat hearts. J Thorac Cardiovasc Surg. 2002;124 (4):775-84.

75. Cai H, Li Z, Goette A, et al. Downregulation of endocardial nitric oxide synthase expression and nitric oxide production in atrial fibrillation: potential mechanisms for atrial thrombosis and stroke. Circulation. 2002;106(22):2854-8

76. Antoniades C, Demosthenous M, Reilly S, et al. Myocardial redox state predicts in-hospital clinical outcome after cardiac surgery effects of short-term pre-operative statin treatment. J Am Coll Cardiol. 2012;59(1):60-70.

77. Xia Y, Dawson VL, Dawson TM, Snyder SH, Zweier JL. Nitric oxide synthase generates superoxide and nitric oxide in argininedepleted cells leading to peroxynitrite-mediated cellular injury. Proc Natl Acad Sci USA. 1996;93(13):6770-4

78. Cardounel AJ, Xia Y, Zweier JL. Endogenous methylarginines modulate superoxide as well as nitric oxide generation from neuronal nitric-oxide synthase: differences in the effects of monomethyl- and dimethylarginines in the presence and absence of tetrahydrobiopterin. J Biol Chem. 2005;280 (9):7540-9.

79. Druhan LJ, Forbes SP, Pope AJ, et al. Regulation of eNOSderived superoxide by endogenous methylarginines. Biochemistry. 2008;47(27):7256-63.
80. Leiper J, Nandi M. The therapeutic potential of targeting endogenous inhibitors of nitric oxide synthesis. Nat Rev Drug Discov. 2011;10(4):277-91.

81. Boger RH, Sydow K, Borlak J, et al. LDL cholesterol upregulates synthesis of asymmetrical dimethylarginine in human endothelial cells: involvement of S-adenosylmethionine-dependent methyltransferases. Circ Res. 2000;87(2):99-105.

82. Forbes SP, Druhan LJ, Guzman JE, et al. Mechanism of 4-HNE mediated inhibition of hDDAH-1: implications in no regulation. Biochemistry. 2008;47(6):1819-26.

83. Cardounel AJ, Cui H, Samouilov A, et al. Evidence for the pathophysiological role of endogenous methylarginines in regulation of endothelial NO production and vascular function. J Biol Chem. 2007;282(2):879-87.

84. Antoniades C, Shirodaria C, Leeson P, et al. Association of plasma asymmetrical dimethylarginine (ADMA) with elevated vascular superoxide production and endothelial nitric oxide synthase uncoupling: implications for endothelial function in human atherosclerosis. Eur Heart J. 2009;30 (9):1142-50.

85. •• Chen CA, Wang TY, Varadharaj S, et al. S-glutathionylation uncouples eNOS and regulates its cellular and vascular function. Nature. 2010;468(7327):1115-8. The authors identify Sgulathionylation as a novel mechanism regulating superoxide production by nitric oxide synthase.

86. Wilson AM, Harada R, Nair N, Balasubramanian N, Cooke JP. Larginine supplementation in peripheral arterial disease: no benefit and possible harm. Circulation. 2007;116(2):188-95.

87. Schulman SP, Becker LC, Kass DA, et al. L-arginine therapy in acute myocardial infarction: the Vascular Interaction With Age in Myocardial Infarction (VINTAGE MI) randomized clinical trial. JAMA. 2006;295(1):58-64.

88. Higashi Y, Sasaki S, Nakagawa K, et al. Tetrahydrobiopterin enhances forearm vascular response to acetylcholine in both normotensive and hypertensive individuals. Am J Hypertens. 2002;15(4 Pt 1):326-32.

89. Stroes E, Kastelein J, Cosentino F, et al. Tetrahydrobiopterin restores endothelial function in hypercholesterolemia. J Clin Invest. 1997;99(1):41-6.

90. Heitzer T, Krohn K, Albers S, Meinertz T. Tetrahydrobiopterin improves endothelium-dependent vasodilation by increasing nitric oxide activity in patients with Type II diabetes mellitus. Diabetologia. 2000;43(11):1435-8.

91. Heitzer T, Brockhoff C, Mayer B, et al. Tetrahydrobiopterin improves endothelium-dependent vasodilation in chronic smokers: evidence for a dysfunctional nitric oxide synthase. Circ Res. 2000;86(2):E36-41.

92. Cosentino F, Hurlimann D, Delli Gatti C, et al. Chronic treatment with tetrahydrobiopterin reverses endothelial dysfunction and oxidative stress in hypercholesterolaemia. Heart. 2008;94 (4):487-92.

93. Porkert M, Sher S, Reddy U, et al. Tetrahydrobiopterin: a novel antihypertensive therapy. J Hum Hypertens. 2008;22 (6):401-7.

94. Levy HL, Milanowski A, Chakrapani A, et al. Efficacy of sapropterin dihydrochloride (tetrahydrobiopterin, 6R-BH4) for reduction of phenylalanine concentration in patients with phenylketonuria: a phase III randomised placebo-controlled study. Lancet. 2007;370(9586):504-10.

95. Trefz FK, Burton BK, Longo N, et al. Efficacy of sapropterin dihydrochloride in increasing phenylalanine tolerance in children with phenylketonuria: a phase III, randomized, double-blind, placebo-controlled study. J Pediatr. 2009;154 (5):700-7.

96. • Cunnington C, Van Assche T, Shirodaria C, et al. Systemic and vascular oxidation limits efficacy of oral tetrahydrobiopterin 
treatment in patients with coronary artery disease. Circulation. 2012, [Epub ahead of print]. This study pairs a randomized controlled trial of two doses of oral BH4 in patients with coronary artery disease with ex vivo and in vitro studies of BH4 oxidation, transport, and effects on NOS coupling. The authors demonstrated that oral BH4 supplementation may be limited by a failure to improve vascular BH4:BH2 ratios.

97. - Moens AL, Ketner EA, Takimoto E, et al. Bi-modal dose-dependent cardiac response to tetrahydrobiopterin in pressure-overload induced hypertrophy and heart failure. J Mol Cell Cardiol. 2011;51(4):564-9. This study confirms earlier findings that BH4 supplementation reverses ventricular pressure overload-induced cardiac hypertrophy and dysfunction. Of critical importance, administration of high-dose BH4 causes the ratio of BH4:BH2 to return toward baseline.
98. Hattori Y, Nakanishi N, Akimoto K, Yoshida M, Kasai K. HMGCoA reductase inhibitor increases GTP cyclohydrolase I mRNA and tetrahydrobiopterin in vascular endothelial cells. Arterioscler Thromb Vasc Biol. 2003;23(2):176-82.

99. Antoniades C, Bakogiannis C, Leeson P, et al. Rapid, direct effects of statin treatment on arterial redox state and nitric oxide bioavailability in human atherosclerosis via tetrahydrobiopterinmediated endothelial nitric oxide synthase coupling. Circulation. 2011;124(3):335-45.

100. Antoniades C, Shirodaria C, Warrick N, et al. 5-methyltetrahydrofolate rapidly improves endothelial function and decreases superoxide production in human vessels: effects on vascular tetrahydrobiopterin availability and endothelial nitric oxide synthase coupling. Circulation. 2006;114(11):1193-201. 